\title{
Gender expression, sexual orientation and pain sensitivity in women
}

\author{
Jacob M Vigil PhD ${ }^{1}$, Lauren N Rowell BA ${ }^{1}$, Charlotte Lutz BA ${ }^{2}$
}

JM Vigil, LN Rowell, C Lutz. Gender expression, sexual orientation and pain sensitivity in women. Pain Res Manag 2014;19(2):87-92.

BACKGROUND: Despite a growing body of literature investigating sex differences with regard to pain, surprisingly little research has been conducted on the influence of various aspects of self-identity, including gender expression and sexual orientation, on pain sensitivity within each sex, particularly among women. In men, dispositional femininity is linked to greater clinical pain and trait masculinity is associated with higher pain thresholds.

OBJECTIVES: To examine whether gender expression and sexual orientation are associated with within-sex differences in ischemic pain sensitivity in healthy young women.

METHODS: A convenience sample of 172 females (mean age 21.4 years; range 18 to 30 years of age; $56.0 \%$ white, $89 \%$ heterosexual) performed an ischemic pain task in counterbalanced order. Desired levels of dispositional femininity for a preferred romantic partner and self-described levels of personal dispositional femininity were measured.

RESULTS: Compared with heterosexual women, lesbian and bisexual women reported lower pain intensity ratings early in the discomfort task. Irrespective of sexual orientation, attraction to more feminine romantic partners and dispositional masculinity were correlated with lower pain intensity, and with higher pain thresholds and tolerance levels.

DISCUSSION: These preliminary findings suggest that within-sex differences in sexual orientation and other aspects of identity, irrespective of biological sex, may be important to consider when examining experimental pain performance and clinical pain experiences.

CONCLUSION: Larger investigations of the psychophysiological relationships among sexual orientation, gender expression and pain sensitivity are warranted. These findings may have implications for differences in clinical pain sensitivity of lesbian and bisexual women compared with heterosexual women.

Key Words: Bisexuals; Experimental pain; Gender; Lesbians; Women's health

T is well established that biological sex modulates pain. Compared 1 with males, females report greater prevalence, frequency and duration of clinical pain and pain-related distress (1-5). Experimental studies show that women are more likely to report lower pain threshold and tolerance, and higher pain intensity associated with various types of noxious stimuli (eg, ischemic, pressure, electrical and thermal $[2-4,6-8])$. The magnitude of these effects varies from moderate to large depending on sample size, the nature of the stimulus, and whether pain sensitivity is indexed according to threshold or tolerance $(2,4,7,9)$. Despite a growing body of literature regarding sex differences in pain, surprisingly little research has been conducted on the influence of gender expression and sexual orientation on pain sensitivity within each sex; this is particularly true among women. To the best of our knowledge, the present study is the first to measure how ischemic pain performance corresponds to variability in aspects of identity (ie, a collection of self-descriptions) including gender expression, preferred gender expression in a romantic partner and sexual orientation in women. The goal of the present study was to use a previous dataset to examine whether trends in these relationships exist to warrant a

\section{L'expression sexuelle, l'orientation sexuelle et la sensibilité à la douleur chez les femmes}

HISTORIQUE : Malgré un nombre croissant de publications sur les différences des sexes sur le plan de la douleur, il existe étonnamment peu de recherches sur l'influence de divers aspects de l'identité de soi, y compris l'expression sexuelle et l'orientation sexuelle, sur la sensibilité à la douleur au sein de chaque sexe, notamment les femmes. Chez les hommes, la féminité décisionnelle est liée à une plus grande douleur clinique, tandis que le trait de masculinité s'associe à des seuils de douleur plus élevés.

OBJECTIFS : Examiner si l'expression sexuelle et l'orientation sexuelle s'associent à des différences sur le plan de la sensibilité à la douleur ischémique chez des jeunes femmes en santé.

MÉTHODOLOGIE : Un échantillon de commodité de 172 femmes (de 18 à 30 ans, d'un âge moyen de 21,4 ans, dont 56,0 \% étaient blanches et 89 \%, hétérosexuelles) a effectué une tâche de douleur ischémique par ordre compensé. Les chercheurs ont mesuré les taux souhaités de féminité décisionnelle d'un partenaire romantique espéré et les taux de féminité décisionnelle autodéclarés.

RÉSULTATS : Les lesbiennes et les bisexuelles déclaraient des classements plus faibles d'intensité de la douleur que les hétérosexuelles au début de la tâche d'inconfort. Quelle que soit leur orientation sexuelle, l'attirance vers des partenaires romantiques plus féminines et la masculinité décisionnelle étaient corrélées avec une intensité de douleur plus faible, des seuils de douleur et un niveau de tolérance plus élevés.

EXPOSÉ : D'après ces observations préliminaires, il peut être important de tenir compte des différences d'un même sexe selon l'orientation sexuelle et d'autres aspects de l'identité, indépendamment du sexe biologique, au moment d'examiner le rendement à la douleur expérimentale et les expériences de douleur clinique.

CONCLUSION : De plus vastes enquêtes sur les relations psychophysiologiques entre l'orientation sexuelle, l'expression sexuelle et la sensibilité à la douleur s'imposent. Ces observations pourraient avoir des conséquences sur les différences de sensibilité à la douleur clinique des lesbiennes et des bisexuelles par rapport aux hétérosexuelles.

larger-scale investigation. The present research will provide the important first step for interpreting how within-sex differences in different aspects of one's self-identity are linked to experimental pain sensitivity, which may expand our understanding of the nature of clinical pain in women.

Several studies have shown that self-described masculinity and femininity are predictive of experimental pain sensitivity $(10,11)$. Gender expression refers to the characteristics in one's personality, appearance and behaviour that are culturally defined as masculine or feminine; this construct is usually measured via self-reported instruments designed to capture individuals's beliefs, behaviours and attitudes about being of a particular sex (12-17). Dispositional femininity has been linked to greater clinical pain in men $(18,19)$ and, in laboratory studies, individuals who rate themselves as possessing higher levels of trait masculinity have higher pain thresholds than individuals who rate themselves as having more feminine traits $(10,20)$. However, most previous studies have not controlled for biological sex and sexual orientation (21), which confounds the ability to measure the influence of gender expression independent of these factors. Although research

\footnotetext{
${ }^{1}$ University of New Mexico, Albuquerque, New Mexico; ${ }^{2}$ University of North Florida, Jacksonville, Florida, USA

Correspondence: Dr Jacob M Vigil, Department of Psychology at the University of New Mexico, 1 University of New Mexico, MSC03 2220,

Albuquerque, New Mexico 87131-1161, USA. Telephone 505-277-0374, fax 505-277-1394, e-mail vigilj@unm.edu
} 
has examined the effects of biological factors, such as gonadal sex hormones, on pain sensitivity (eg, fluctuations across the menstrual cycle $[22,23])$, other salient aspects of one's identity, including gender expression, sexual orientation and preferred gender expression in romantic partner, have yet to be studied, particularly in women. Understanding individual differences in women's experimental pain sensitivity is clinically important because experimental pain has been shown to be associated with endogenous regulatory mechanisms such as sympathetic functioning (24); women are more susceptible to conventional risk factors (ie, body weight and age) that exacerbate musculoskeletal and inflammatory pain; and because women utilize a disproportionate amount of health care services in the United States (25).

Understanding the differences in women's pain according to sexual orientation and gender expression may help to explain health care disparities. It is well established in the literature that ethnic minorities have increased sensitivity to pain; this is hypothesized to be related to discrimination $(24,26,27)$. It is also well established that lesbian and bisexual women are exposed to higher levels of unpredictable, episodic and daily social stress, discrimination and harassment than heterosexuals (28-30). The present study is, to our knowledge, the first to explore pain sensitivity and tolerance in lesbian and bisexual women.

Previous research on the influence of gender on pain performance has mainly focused on reduced pain tolerance in men who describe themselves as more feminine (21). Therefore, the current study focuses on the relationship among core components of self-identity including self-described gender expression and preferred trait levels of gender expression in romantic partners, sexual orientation and ischemic pain performance in healthy young women. These results may have implications for regulating clinical pain because experimental pain sensitivity is predictive of clinical pain $(31,32)$. It is hypothesized that lesbian and bisexual women will be less sensitive to pain than heterosexual women. Regardless of sexual orientation, women who endorse a preference for more feminine romantic partners and women who describe themselves as more masculine are predicted to report higher pain thresholds and pain tolerance, and lower pain intensity levels than women who report attraction for more masculine romantic partners and rate themselves as possessing more feminine dispositions. These findings will provide initial information on the potential links between fundamental components of identity (including gender expression, sexual orientation and preferred gender expression in potential partners) and experimental pain sensitivity that operate irrespective of biological sex.

\section{METHODS}

\section{Participants}

The study protocol was approved by the Institutional Review Board at the University of North Florida (Jacksonville, Florida, USA) and informed written consent was obtained from all participants. Undergraduate students were recruited for a study investigating "individual differences in pain perception" and received extra credit for an introductory psychology course for their participation. Participants self-identified contraindications to the ischemic pain task, which included any history of illness or pathology related to peripheral vascular or neuropathic abnormalities, psychological distress/diagnoses, excessive alcohol use in the week before participation, and current medication use related to vascular or pain-related ailments. Participants reporting any contraindication were excluded from the study. Participants were included in the study if they clearly indicated their biological sex as female (ie, participants who described themselves as male or transgendered were excluded from the study) and if they were $\leq 30$ years of age. In total, 172 young adult women met these criteria for inclusion in the study (range 18 to 30 years of age; mean age $21 \pm 2.5$ years; $56 \%$ non-Hispanic white). Sexual orientation was selfreported; eight participants $(4.7 \%)$ described themselves as lesbian, 11 participants $(6.4 \%)$ described themselves as bisexual and the remainder of participants (89\%) described themselves as heterosexual, which is similar to national averages (33). The heterosexual and the combined lesbian and bisexual groups did not differ according to age or ethnic background $(\mathrm{P}>0.30)$.

\section{Ischemic procedure}

Participants completed questionnaires and the ischemic procedure. These two parts of the procedure were counterbalanced to ensure that the questionnaires did not affect pain tolerance ratings. During the ischemic procedure, one male and one female researcher were present to control for audience effects on experimental pain performance (8). On entering the ischemic task room, researchers first obtained an initial pain assessment score (visual analogue scale [VAS] 1) on a standard VAS (0 ['no pain'] to 10 ['worst pain imaginable']). Participants were then seated at a computer and a computer program was initiated. The program provided instructions about how to indicate discomfort and pain thresholds, pain intensity ratings and pain tolerance. Participants were informed by the program that when the task begins to press radio buttons to indicate the instance (measured in time latency) that they first experienced felt discomfort (discomfort threshold), felt pain (pain threshold) and desired to stop the task because they were no longer willing or able to tolerate the pain (pain tolerance). The pain assessment program also prompted participants to indicate their pain intensity ratings ( 0 to 10 ) every $30 \mathrm{~s}$ throughout the the ischemic procedure (on an audio prompt and illumination of the pain VAS). There was no time visible to participants on the computer screen or in the testing room to ensure that participants were unaware of how much time elapsed during the procedure. Participants were informed before they began that they could end the pain task at any time if they were no longer willing or able to continue.

Once participants verbally indicated their comprehension of the task and how to use the computer interface, the ischemic pain task was initiated by first asking participants to remove any jewelry or accessories from their nondominant arm. Participants were then asked to raise their arm above their head (so that the elbow was at ear level) for $60 \mathrm{~s}$ to ensure adequate limb desanguination. A sphygmomanometer (blood pressure cuff) was then placed on the participants' forearm $5 \mathrm{~cm}$ above the elbow crease and manually inflated to $200 \mathrm{mmHg}$ over a period of 20 s. Participants then lowered and rested their arm at a horizontal position, and provided an initial pain assessment on the computer screen (VAS2). They were then instructed to start making continuous soft-fist movements (described as gently touching the fingertips to the palm of the hand every $3 \mathrm{~s}$ ) and to continue throughout the duration of the ischemic procedure. The authors' laboratory has found that continuous hand flexing motions are functionally similar to hand-grip exercises used in other studies for quickly and reliably producing high levels of pain sensations. The initial pain assessment (VAS2) activated the program, which prompted (via beep sounds and VAS illumination) participants to indicate their pain ratings every $30 \mathrm{~s}$, over a maximum of $5 \mathrm{~min} 30 \mathrm{~s}$ (VAS 3 through 13). Participants were unaware of this time limit, which was used to ensure the safety of the participants. On termination or after $5 \mathrm{~min} 30 \mathrm{~s}$, the cuff was deflated over a $30 \mathrm{~s}$ period.

Following the ischemic procedure, participants were instructed to relax for $5 \mathrm{~min}$ to allow their pain to subside to normal levels. After $5 \mathrm{~min}$ and/or adequate resting, participants were asked to complete a final pain intensity rating (VAS14) to ensure the absence of any discomfort that resulted from the ischemic procedure for the participants' safety. The entire discomfort task took between $6 \mathrm{~min}$ and $15 \mathrm{~min}$ to complete.

\section{Measures}

The questionnaire was created by the authors' laboratory as part of a larger survey ( $>200$ items) that covered a wide range of (non-genderrelated) personal and psychological topics; the individual items that pertained to the current study included sex, age, ethnicity, self-identified sexual orientation (ie, heterosexual, lesbian or bisexual) and two items about self-identified gender expression that used the concepts of masculinity/femininity to capture two separate components of selfidentity. The first item asked participants to rate the level of masculinity and femininity preferred in a romantic partner; the second item asked 
participants to indicate their self-described levels of masculinity and femininity. Each of the items was scored on a 10-point Likert scale ranging from extremely masculine to extremely feminine, which is similar to other techniques used for measuring gender expression (13).

Depression has been shown to correlate with pain tolerance $(34,35)$, and this was measured using the The Center for Epidemiologic Studies Depression Scale (36). The instrument consists of 20 items, which are scored on a four-point Likert scale $(\alpha=0.87)$. The overall depression score was not correlated with any of the pain measurement $(\mathrm{P}>0.10)$, and the depression scores did not differ across the sexual orientation groups $(\mathrm{P}=0.95)$, or between the heterosexual women and the combined lesbian and bisexual women $(\mathrm{P}=0.75)$.

A questionnaire was also used to estimate the women's fertility levels on the day of participation. This was performed by asking participants to indicate the dates of their last three menstrual cycles on calendars and estimating their level of fertility according to conventional descriptions (37). On the basis of a 28-day standardized cycle, the women were divided into a high-fertility group (day 8 to day $20 ; n=35$ ), a low-fertility group (day 1 to day 7 and day 21 to day $28 ; n=46$ ) or a hormonal contraceptive use group $(n=91)$. The proportions of participants across the three fertility conditions did not differ among the heterosexual women and the combined lesbian and bisexual women $(\mathrm{P}=0.83)$. Finally, smokers were included in the study; however, the proportion of smokers (defined as currently smoking twice per month or more) did not differ among the heterosexual women or the combined lesbian and bisexual women $(\mathrm{P}=0.36)$; pain threshold and tolerance did not differ according to smoking status $(\mathrm{P}>0.10)$.

\section{Data analyses}

The pain scores included the participant's discomfort threshold, pain threshold, pain tolerance (measured in seconds post-arm resting/hand flexing) and the pain intensity scores during the first 2 min of the task (VAS2 to VAS5). Higher-intensity scores and lower threshold and tolerance scores are interpreted as indicating greater pain sensitivity (reverse effect sizes of threshold and tolerance scores reflect greater pain sensitivity). $\chi^{2}$ analyses were performed to assess for order effects of the survey and ischemic task, and no differences were observed for any of the pain scores $(P>0.10)$. Because the proportions of individuals with different sexual orientations were unequal and the gender-related scores were not normally distributed (Figure 1), nonparametric statistics are reported. Due to the small proportion of lesbian and bisexual women, these subgroups were combined and contrasted with heterosexual women for the primary analyses corresponding to pain sensitivity. Relationships among variables were measured using Spearman $R$ correlations $\left(r_{s}\right)$ and differences among groups were measured using Mann-Whitney $U$ tests. Effect sizes are described as correlation coefficients $(r=Z / \sqrt{ } n)$.

\section{RESULTS}

\section{Variability in gender expression}

Preference for masculine romantic partners and dispositional femininity were only slightly correlated for the entire sample $\left(r_{s}=0.32\right.$; $\mathrm{P}<0.01$ ). Comparing heterosexual and combined lesbian and bisexual women separately revealed that attraction to more masculine romantic partners and dispositional femininity were only significantly correlated in the heterosexual group $\left(r_{s}=0.27 ; \mathrm{P}<0.01\right)$, and there was a trend for a similar correlation in the combined lesbian and bisexual group $\left(r_{s}=0.41 ; P=0.09\right)$. The distribution of scores for the genderbased items for the heterosexual and combined lesbian and bisexual groups is shown in Figures $1 \mathrm{~A}$ and $1 \mathrm{~B}$, respectively.

As shown in Figure 1A, preferred levels of gender expression in one's sexual partner ranged from 1 (extremely masculine) to 5 in heterosexual women, and from 4 to 10 (extremely feminine) in lesbian and bisexual women. The frequency distribution was positively skewed in the heterosexual group ( median $=1$, range $=4$; skewness $=3.14$, $\mathrm{SE}=0.20$; kurtosis $=11.04, \mathrm{SE}=0.39)$ and $81 \%$ of these women were attracted to extremely masculine romantic partners (a score of 1 on

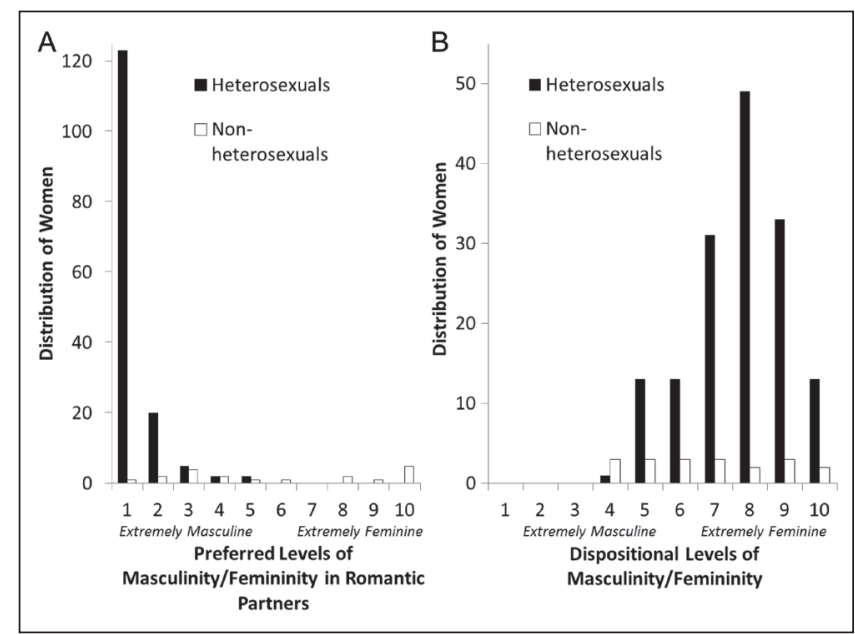

Figure 1) Distribution of gender expression preferences and dispositional gender expression in heterosexual women and lesbian and bisexual women

the 10 -point scale). The frequency distribution in the lesbian and bisexual group was bimodal $($ median $=5$, range $=9$; skewness $=0.13$, $\mathrm{SE}=0.52$; kurtosis $=-1.72, \mathrm{SE}=1.01)$ and a Mann-Whitney test indicated a significant group difference between heterosexual women and lesbian and bisexual women in this measure $(U=161.50, Z=-8.03$; $\mathrm{P}<0.01$ ), with lesbian and bisexual women preferring more feminine partners than heterosexual women. Comparisons of romantic preferences between lesbian and bisexual women showed that bisexual women reported a greater preference for feminine romantic partners $($ median $=10$, range $=9)$ compared with lesbian women $($ median $=3$, range $=6, \mathrm{U}=11.50, \mathrm{Z}=-2.72 ; \mathrm{P}=0.01$ ).

Dispositional gender expression ranged from 4 to 10 (extremely feminine), and this construct was normally distributed around the mean in the heterosexual group (median $=8$, range $=6$; skewness $=-0.45, \mathrm{SE}=0.20$; kurtosis $=-0.29, \mathrm{SE}=0.39)$ and uniform around the mean in the combined lesbian and bisexual group (median $=7$, range $=6$; skewness $=0.14, \mathrm{SE}=0.52$; kurtosis $=-1.22, \mathrm{SE}=1.01)$. $\mathrm{A}$ significant group difference between heterosexual women and lesbian and bisexual women was also observed for this construct $(\mathrm{U}=1041.50$, $\mathrm{Z}=-2.06 ; \mathrm{P}=0.04)$. Comparisons between the lesbian and bisexual women showed that the two groups did not report a median difference in dispositional gender expression (medians $=6$ and 7 , ranges $=6$, $\mathrm{U}=39.00, \mathrm{Z}=-0.42 ; \mathrm{P}=0.68)$.

\section{Sexual orientation, gender expression and pain sensitivity}

The median pain intensity ratings for the heterosexual women and the lesbian and bisexual women for each of the first four pain intensity ratings obtained during the discomfort task are shown in the first three columns of Table 1 . As shown in Table 1, Mann-Whitney $U$ tests revealed significant group differences in pain intensity ratings at $60 \mathrm{~s}$ and $90 \mathrm{~s}$ into the pain task, with lesbian and bisexual women reporting lower pain scores compared with heterosexual women $\left(r_{s}=0.17\right.$ and 0.19). The median threshold and tolerance scores for heterosexual women and lesbian and bisexual women are presented in Table 1. Mann-Whitney $U$ tests did not reveal any significant group differences for these measures; however, there was a trend toward lower median pain threshold scores among the heterosexual group $(U=618.00$, $\mathrm{P}=0.07, \mathrm{r}=0.15$ ).

Spearman correlations between the pain ratings and the two gender items (preferred levels of femininity in romantic partners and trait levels of femininity) for the entire sample are also presented in Table 1 . Attraction to more feminine romantic partners was related to lower pain intensity ratings between $1 \mathrm{~min}$ and $2 \mathrm{~min}$ into the task. Similarly, there was a modest association between self-described masculinity and lower pain intensity ratings during the first minute of the task. When the heterosexual women and the lesbian and bisexual women 


\begin{tabular}{|c|c|c|c|c|c|}
\hline \multirow[b]{3}{*}{ Pain variable§ } & \multirow{2}{*}{\multicolumn{3}{|c|}{ Group differences $^{\dagger}$}} & \multicolumn{2}{|c|}{ Correlations $\left(r_{s}\right)^{\ddagger}$} \\
\hline & & & & \multirow{2}{*}{$\begin{array}{c}\text { Masculine versus } \\
\text { feminine preferred } \\
\text { partners }\end{array}$} & \multirow{2}{*}{$\begin{array}{c}\text { Dispositional } \\
\text { masculinity versus } \\
\text { femininity }\end{array}$} \\
\hline & Heterosexual & Lesbian and bisexual & z & & \\
\hline VAS $60 \mathrm{~s}, \mathrm{n}=137, \mathrm{n}=17$ & $4.00(8)$ & $2(7)$ & $-2.08^{*}$ & $-0.21^{* *}$ & $0.22^{* *}$ \\
\hline VAS $90 \mathrm{~s}, \mathrm{n}=111, \mathrm{n}=16$ & $5(9)$ & $3.50(7)$ & $-2.14^{*}$ & $-0.28^{* *}$ & 0.07 \\
\hline VAS $120 \mathrm{~s}, \mathrm{n}=85, \mathrm{n}=15$ & $5(9)$ & $6(8)$ & -1.39 & $-0.26^{* *}$ & 0.05 \\
\hline Pain threshold, $n=136, n=19$ & $105.42(418)$ & $126.21(414)$ & -1.79 & 0.16 & $-0.20^{* *}$ \\
\hline Pain tolerance, $n=144, n=19$ & $138.75(624)$ & $171.16(512)$ & -1.25 & $0.17^{*}$ & -0.15 \\
\hline
\end{tabular}

${ }^{*} P<0.05 ;{ }^{* *} P<0.01 ;{ }^{\dagger}$ Group differences in median values (ranges in parentheses) for the pain sensitivity scores; ${ }^{\ddagger}$ Spearman correlations among the entire sample; $\S$ Row labels show the number of participants in each sexual orientation group (heterosexual women and lesbian and bisexual women, respectively); VAS Visual analogue scale

were compared separately, a slight correlation was revealed between attraction to feminine partners and lower pain intensity levels at $90 \mathrm{~s}$ $\left(r_{s}=0.22 ; \mathrm{P}=0.02\right)$ and $120 \mathrm{~s}\left(r_{s}=0.23 ; \mathrm{P}=0.04\right)$ into the pain task for the heterosexual group. Dispositional masculinity was also associated with lower pain intensity ratings at $30 \mathrm{~s}\left(\mathrm{r}_{\mathrm{s}}=0.19 ; \mathrm{P}=0.02\right)$ and $60 \mathrm{~s}\left(\mathrm{r}_{\mathrm{s}}=0.19\right.$; $\mathrm{P}=0.03$ ) into the task in the heterosexual group. The gender-based items were not associated with pain intensity scores in the combined lesbian and bisexual group $(\mathrm{P}>0.10)$.

Finally, Table 1 shows that, among the entire sample, attraction to feminine romantic partners was similarly associated with higher pain tolerance, and dispositional masculinity was associated with higher pain threshold. When the heterosexual women and lesbian and bisexual women were compared separately, a trend for a relationship between attraction for more feminine partners and higher pain tolerance was found in the heterosexual group only $\left(r_{s}=0.16 ; P=0.06\right)$. In the lesbian and bisexual group, dispositional masculinity was associated with higher pain threshold $\left(r_{s}=-0.66 ; P=0.02\right)$, and there was a trend for a relationship between dispositional masculinity and higher pain tolerance $\left(r_{s}=-0.49 ; \mathrm{P}=0.06\right)$.

\section{DISCUSSION}

The present preliminary study shows that ischemic pain performance is associated with sexual orientation, dispositional gender expression and preferred gender expression in romantic partners among healthy young women. The rates of self-identified heterosexual, lesbian and bisexual orientations of women in the current sample were comparable with national averages (33). Compared with heterosexual women, lesbians and bisexual women reported lower pain intensity ratings. Analyzing the heterosexual women and the lesbian and bisexual women separately showed that, among heterosexual women, attraction to more feminine romantic partners was associated with lower pain intensity ratings early in the ischemic discomfort task, and there was a slight association between self-described masculinity and lower pain intensity ratings. Similar associations emerged between attraction to more feminine romantic partners and higher pain tolerance in the heterosexual group, and for dispositional masculinity and higher pain threshold and tolerance levels in the lesbian and bisexual group. These findings provide preliminary support for the hypothesis that, irrespective of biological sex, various other aspects of gender are associated with ischemic pain performance.

These findings suggest that larger-scale studies of aspects of identity, such as gender expression and sexual orientation, would be fruitful and may lead to a better understanding of individual differences in both experimental and clinical pain, and related health problems in women. According to a recent report from The Institute of Medicine of the National Academies, lesbian, gay, bisexual and transgender individuals comprise a patient subgroup that is at greater risk than the general population to experience adverse health outcomes (38). For example, among women, lesbians and bisexuals experience higher rates of breast cancer and heart disease compared with heterosexuals, and these added risks are linked to endogenous behavioural factors including smoking, binge drinking, unhealthy diet and obesity $(39-41)$.

Lower quality of health is also speculated to stem from exogenous factors such as higher rates of actual or anticipated discrimination and lower-quality health care from medical providers. Individuals who experience prejudice and discrimination, and individuals who conceal a same-sex orientation are more likely to show occupational distress and lower general health (42-45). Stigmatization of sexual minorities, including discrimination, violence, expectations of rejection and internalized homophobia, have been found to negatively affect both mental and physical health $(46,47)$, and result in psychological distress (48-51). Women of sexual minorities are more likely to underutilize health care services and to avoid general preventive care, and these patterns may be linked to repeated experiences of homophobia and heterosexism within the health care system (52-54). Additional minority identities, such as ethnic minority status, appear to compound the increased risk of morbidity in lesbian and bisexual women (55), although it is unclear at this time how these added risk factors are related to endogenous (eg, personal) and/or exogenous (eg, interpersonal) factors. Nonetheless, disparities in patient pain experience is an important public health issue that is both costly to society and important for understanding potential causes of undertreatment of pain-related conditions for some women.

The current study highlights the potential importance of dispositional gender expression and preferred gender expression in romantic partners for understanding sex differences in clinical and experimental pain sensitivity $(8,56)$. The study provides preliminary evidence that several components of gender and identity are each predictive of experimental pain sensitivity, which may actually interact with (rather than merely result from) biological sex to influence pain behaviours. For example, research has found that women show a stronger association between reflexive (eg, facial) pain behaviours and reflective pain reports, suggesting that females may be more sensitive to exaggerate the expression of pain behaviours compared with males, who may instead be more sensitive to constrain the display of pain in general (57). Other investigations have shown that women are more sensitive to both dosage and type of analgesic medication (58); however, less is known about how fundamental components of sexuality and gender within each sex, not directly related to chromosomal identity, may contribute to variability in pain perception and overall health.

A conventional explanation of sex differences in pain behaviours (ie, verbal and nonverbal pain gestures) is that they are driven by learned role expectations (59). This interpretation does not, however, account for the cross-cultural and ontogenetic nature of the differences; sex differences in experimental pain sensitivity persist independent of salient cultural factors such as ethnicity (55), and differences in pain behaviours have been observed in infancy $(60,61)$. Therefore, a 
more likely explanation for the nature of the differences is that they are driven by biologically functional and specialized (sex-typical) behavioural strategies and corresponding communication styles $(56,62-64)$. Several studies have shown that pain sensitivity covaries with fluctuations in circulating sex hormones levels $(22,23)$; however, these effects have yet to be examined with respect to gender expression. On the basis of a social communication model of sex differences in pain behaviours (64), there is predicted to be a multitude of associations between pain perception and psychological constituents of biological sex including personal identity formation and preferred gender expression in potential partners, highlighted in the current study.

Some theorists have suggested that the evolved processes underlying distinct components of sexuality, such as preferred gender expression in potential reproductive partners and dispositional characteristics (eg, affectional bonding), are functionally independent (65) and may, thus, share unique relationships with other aspects of biological functioning including pain sensitivity. This thesis is consistent with the current preliminary findings that preference for more masculine/feminine romantic partners and trait levels of gender expression were only slightly correlated, and that regardless of sexual orientation, preference for, and dispositional gender expression were independently associated with pain intensity, threshold and tolerance reports. These findings are consistent with the hypothesis that cognitive representations and/or reports of gender may mediate the relation between biological (ie, chromosomal) sex and variability in pain sensitivity. Psychological constructs, such as gender expression, preferred gender expression in significant relationship partners and sexual orientation, may, therefore, play a role in women's pain experience somewhat independent of physical tissue damage, and in ways that could exacerbate clinical pain.

The limitations of the present study included a very small sample size of lesbian and bisexual females compared with heterosexual females, although the rates of self-identified heterosexual, lesbian and bisexual orientations of the sample were comparable with national averages (33). It is also important to consider that trait levels of dispositional femininity and masculinity were relatively homogenous for both the heterosexual group and the lesbian and bisexual group and were skewed toward more self-described feminine dispositions; it is unknown whether these patterns are typical for women with different demographic characteristics and cultural backgrounds. Sexual-majority women homogenously preferred extremely masculine partners, which may limit the generalizability of the findings for women with more diverse and varied identities (66). A further limitation was that dispositional masculinity/femininity and preference of gender expression in romantic partners were measured using Likert-style scales and other psychometric techniques (eg, factor-analyzed personality assessments) may be more adept at capturing additional components of personal identities such as appearance, gender roles and emotional expression (67). A further limitation of the study and similar investigations of this nature is that lesbian and bisexual women were combined for analyses. Larger-scale studies should recruit more bisexual and lesbian women to examine these distinct subgroups individually. Finally, the hand-grip component of the ischemic task was not standardized, which could have produced a scenario in which individuals squeeze with less force as they experience more pain, effectively lowering the intensity of the painful stimulus for some women. It is also possible that simultaneously rating pain and completing the ischemic task could have distracted the participants and increased pain tolerance. If these confounds occurred, then they likely would have affected all participants equally. However, due to these limitations, the study should be considered to be preliminary, yet useful for informing future research on identity formation and pain perception.

\section{CONCLUSION}

Our findings show that within-sex variability in gender expression and sexual orientation in women is associated with experimental pain performance. If this observation is confirmed by future larger studies, these results may have important implications for understanding the determinants of individual differences in pain perception and for guiding individualized pain treatment options. Future research will benefit by comparing lesbian and bisexual and majority subgroups separately so as to not obfuscate important distinctions across individuals and adding measures of psychosocial distress (eg, discrimination). Moreover, the findings would suggest that individual differences in gender and sexual orientation, irrespective of biological sex, may be important to consider when examining, comparing and interpreting individual and group differences in experimental pain performance and clinical pain experiences.

DISCLOSURES: There was no funding to support this work. The authors have no conflicts of interest to declare.

ACKNOWLEDGEMENTS: The authors thank David Wilson at the University of North Florida for designing the ischemic pain measurement software.

\section{REFERENCES}

1. Unruh AM. Gender variations in clinical pain experience. Pain 1996;65:123-67.

2. Berkley KJ. Sex differences in pain. Behav Brain Sci 1997;20:371-80.

3. Fillingim RB, Edwards RR, Powell T. Sex-dependent effects of reported familial pain history on recent pain complaints and experimental pain responses. Pain 2000;86:87-94.

4. Riley III JL, Robinson ME, Wise EA, Myers CD, Fillingim RB. Sex differences in the perception of noxious experimental stimuli: A meta-analysis. Pain 1998;74:181-7.

5. Ruau D, Liu LY, Clark JD, Angst MS, Butte AJ. Sex differences in reported pain across 11,000 patients captured in electronic medical records. J Pain 2012;13:228-34.

6. Fillingim RB, Maixner W. The influence of resting blood pressure and gender on pain responses. Psychosom Med 1996;58:326-32.

7. Shinal RM, Fillingim RB. Overview of orofacial pain: Epidemiology and gender differences in orofacial pain. Dent Clin North America 2007;51:1-18.

8. Vigil JM, Coulombe P. Biological sex and social setting affects pain intensity and observational coding of other people's pain behaviors. Pain 2011;152:2125-30

9. Fillingim RB, King CD, Ribeiro-Dasilva MC, Rahim-Williams B, Riley III JL. Sex, gender, and pain: A review of recent clinical and experimental findings. J Pain 2009;10:447-85.

10. Myers CD, Riley III JL, Robinson ME, Sheffield D. Cardiovascular reactivity and gender-role: Contributions to experimental pain report. Psych Med 2001;63:545-50.

11. Bernardes SF, Keogh E, Lima ML. Bridging the gap between pain and gender research. A selective literature review. Eur J Pain 2009;12:427-40.

12. Grossman AH, D'augelli AR, Salter NP. Male-to-female transgender youth: Gender expression milestones, gender atypicality, victimization, and parents' responses. J GLBT Family Studies 2004;2:71-92.

13. Lehavot K, Molina Y, Simoni JM. Childhood trauma, adult sexual assault, and adult gender expression among lesbian and bisexual women. Sex Roles 2012;67:272-84.

14. Levitt HM, Puckett JA, Ippolito MR, Horne SG. Sexual minority women's gender identity and expression: Challenges and supports. J Lesbian Studies 2012;16:153-76.

15. Rosenkrantz PS, Vogel H, Bee I, Broverma, Broverman D. Sex-role stereotypes and self-concepts in college students. J Consult Clin Psych 1968;32:287-95

16. Unger RK. Toward a redefinition of sex and gender. Am Psychol 1979;34:1085-94.

17. Deaux K. Sex and gender. Ann Rev Psych 1985;36;49-81.

18. Trudeau K, Danoff-Burg S, Revenson T, Paget S. Agency and communication in people with rheumatoid arthritis. Sex Roles 2003;49:303-11

19. Applegate KL, Keefe FJ, Siegler IC, et al. Does personality at college entry predict number of reported pain conditions at midlife? A longitudinal Study. J Pain 2005;6:92-7.

20. Otto MW, Dougher MJ. Sex differences and personality factors in responsivity to pain. Percep Motor Skills 1985;61:383-90.

21. Alabas OA, Tashani OA, Tabasam G, Johnson MI. Gender role affects experimental pain responses: A systematic review with meta-analysis. Eur J Pain 2004;16:1211-23. 
22. Fillingim RB, Maixner W, Girdler SS, et al. Ischemic but not thermal pain sensitivity varies across the menstrual cycle. Psychosom Med 1997;59:512-20.

23. Okifuji A, Turk DC. Sex hormones and pain in regularly menstruating women with fibromylgia syndrome. J Pain 2006; 7:851-9.

24. Rowell LN, Mechlin B, Ji E, Addamo M, Girdler SS. Asians differ from non-Hispanic whites in experimental pain sensitivity. Eur J Pain 2011;15:764-71.

25. Lautenbacher S. Sex-related differences in clinical and experimental muscle pain. In: Graven-Nielsen TL, Arendt-Nielsen SS, Mense S, eds. Fundamentals of Musculoskeletal Pain. Seattle: IASP Press 2008.

26. Campbell CM, Edwards RR, Fillingim RB. Ethnic differences in responses to multiple experimental pain stimuli. Clin J Pain 2005;113:20-6.

27. Mechlin M, Maixner W, Light K, Fisher J, Girdler S. African Americans show alterations in endogenous pain regulatory mechanisms and reduced pain tolerance to experimental pain procedures. Psychosom Med 2005;67:948-56

28. Brogan DJ, Frank E, Elon L, Sivanesan P, O'Hanlan KA. Harassment of lesbians as medical students and physicians. JAMA 1999;282:1290, 1292.

29. D'Augelli AR, Hershberger SL, Pilkington NW. Lesbian, gay, and bisexual youth and their families: Disclosure of sexual orientation and its consequences. Am J Orthopsychiatry 1998;68:361-71.

30. Pilkington NW, D'Augelli AR. Victimization of lesbian, gay, and bisexual youth in community settings. Am J Community Psychol 1995;23:34-56.

31. D'Antono B, Ditto B, Rios N, Moskowitz DS. Risk for hypertension and diminished pain sensitivity in women: Autonomic and daily correlates. Int J Psychophysiol 1999;31:175-87.

32. Edwards RR, Doleys DM, Fillingim RB, Lowery D. Ethnic differences in pain tolerance: Clinical implications in a chronic pain population. Psychosom Med 2001;63:316-23.

33. Chandra A, Mosher WD Copen C. Sionean C. Sexual behavior, sexual attraction, and sexual identity in the United States: Data from the 2006-2008 National Survey of Family Growth. National Center for Health Statistics. Natl Health Stat Report 2011:1-36.

34. Adler G, Gattaz WF. Pain perception threshold in major depression. Biol Psychiatry 1993;34:687-9.

35. Lautenbacher S, Spernal J, Schreiber W, Krieg JC. Relationship between clinical pain complaints and pain sensitivity in patients with depression and panic disorder. Psychosom Med 1999;61:822-7.

36. Radloff LS. The CES-D scale: A self-report depression scale for research in the general population. Applied Psych Measure 1997; 1:385-401.

37. Bressan P, Stranieri D. The best men are (not always) already taken: Female preference for single versus attached males depends on conception risk. Psychol Sci 2008;19:145-51.

38. Committee on Lesbian, Gay, Bisexual, and Transgender Health Issues and Research Gaps and Opportunities: The health of lesbian, gay, bisexual, and transgender people: Building a foundation for better understanding. Institute of Medicine. Washington, DC: The National Academies Press, 2001.

39. Diamant AL, Wold C, Spritzer K, Gelberg L. Health behaviors, health status, and access to and use of health care: A populationbased study of lesbian, bisexual, and heterosexual women. Archiv Fam Med 2000;9:1043-51.

40. Case P, Austin S, Hunter DJ, et al. Sexual orientation, health risk factors, and physical functioning in the Nurses' Health Study II. J Women Health 2004;13:1033-47.

41. Valanis BG, Bowen DJ, Bassford, T, Whitlock E, Charney P, Carther RA. Sexual orientation and health: Comparisons in the women's health initiative sample. Archiv Fam Med 2000;9:843-53.

42. Cole SW. Social threat, personal identity, and physical health in closeted gay men. In: Omoto AM, Kurtzman HS, eds. Sexual Orientation and Mental Health: Examining identity and development in lesbian, gay, and bisexual people. Contemporary Perspectives on Lesbian, Gay, and Bisexual Psychology. Washington, DC: American Psychological Association, 2006:245-67.

43. Sandfort TM, H. Bos H, Vet R. Lesbians and gay men at work: Consequences of being out. In: Omoto AM, Kurtzman HS, eds. Sexual Orientation and Mental Health: Examining identity and development in lesbian, gay, and bisexual people. Washington, DC: APA Press, 2006.
44. Kuyper L, Fokkema T. Minority stress and mental health among Dutch LGBs: Examination of differences between sex and sexual orientation. J Couns Psych 2011;58:222-33.

45. Lehavot K, Simoni JM. The impact of minority stress on mental health and substance use among lesbian and bi-sexual women. J Consult Clin Psych 2011;79:159-70.

46. Rosario M, Rotheram-Borus MJ, Reid H. Gay-related stress and its correlates among gay and bisexual male adolescents of predominantly black and hispanic background. J Community Psych 1996;24:136-59.

47. DiPlacido J. Minority stress among lesbians, gay men, and bisexuals: A consequence of heterosexism, homophobia, and stigmatization. In: Gregory E, Herek M, eds. Stigma and Sexual Orientation: Understanding prejudice against lesbians, gay men, and bisexuals. Thousand Oaks: Sage, 1998.

48. Díaz RM, Ayala G, Bein E, Henne BV, Marin. The impact of homophobia, poverty, and racism on the mental health of gay and bisexual Latino men: Findings from 3 US cities. Am J Pub Health 2001;91:927-32.

49. Hatzenbuehler ML, Nolen-Hoeksema S, Erickson SJ. Minority stress predictors of HIV risk behavior, substance use, and depressive symptoms: Results from a prospective study of bereaved gay men. Health Psych 2008;24:455-62.

50. Mays VM, Cochran SD. Mental health correlates of perceived discrimination among lesbian, gay, and bisexual adults in the United States. Am J Pub Health 2001;91:1869-76.

51. Morris JF, Balsam KF. Lesbian and bisexual women's experiences of victimization: Mental health, revictimization, and sexual identity development. J Lesbian Studies 2007;7:67-85.

52. Cochran SD. Emerging issues in research on lesbians' and gay men's mental health: Does sexual orientation really matter? Am Psych 2001;56:931-47.

53. Mays VM, Yancey AK, Cochran SD, Weber M, Fielding JE. Heterogeneity of health disparities among African American, Hispanic, and Asian American women: Unrecognized influences of sexual orientation. Am J Pub Health 2002;92:632-9.

54. McNair RP. Lesbian health inequalities: A cultural minority issue for health professionals. Med J Australia 2003;178:643-5.

55. Kim H, Neubert JK, San Miguel A, et al. Genetic influence on variability in human acute experimental pain sensitivity associated with gender, ethnicity and psychological temperament. Pain 2004;109:488-96.

56. Vigil JM. Current states of opinion and future directions on the epidemiology of sex differences in human pain. Pain Res Manag 2011;16:317-9.

57. Kunz M, Gruber A, Lautenbacher S. Sex differences in facial encoding of pain. J Pain 2006;7:915-28.

58. Paller CJ, Campbell CM, Edwards RR, Dobs AS. Sex-based differences in pain perception and treatment. J Pain Med 2009;10:289-99.

59. Giles BE, Walker JS. Sex differences in pain and analgesia. Pain Rev 2000;7:181-93.

60. Guinsburg R, de Araújo Peres C, Branco de Almeida MF, et al. Differences in pain expression between male female newborn infants. Pain 2000;85:127-33.

61. Fuller BF. Infant gender differences regarding acute established pain. Clin Nurs Res 2002;11:190-203.

62. Vigil JM. Asymmetries in the social styles and friendship preferences of men and women. Human Nature 2007;18:143-61.

63. Vigil JM. Sex differences in affect behaviors, desired social responses, and accuracy at understanding the social desires of other people. Evol Psych 2008;6:506-522.

64. Vigil JM. A socio-relational framework of sex differences in the expression of emotion. Behav Brain Sci 2009;32:375-428.

65. Diamond LM What does sexual orientation orient? A biobehavioral model distinguishing romantic love and sexual desire. Psych Rev 2003;110:173-92.

66. Tate CC. Considering lesbian identity from a social-psychological perspective: Two different models of "being a lesbian". J Lesbian Studies 2012;16:17-29.

67. Lehavot K, King KM, Simoni JM. Development and validation of a gender expression measure among lesbian and bi-sexual women. Psych Women Quart 2011;35:381-400. 


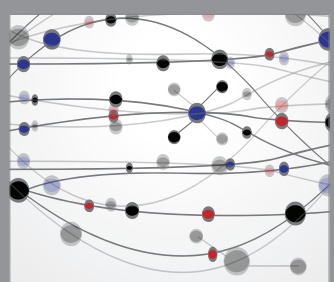

The Scientific World Journal
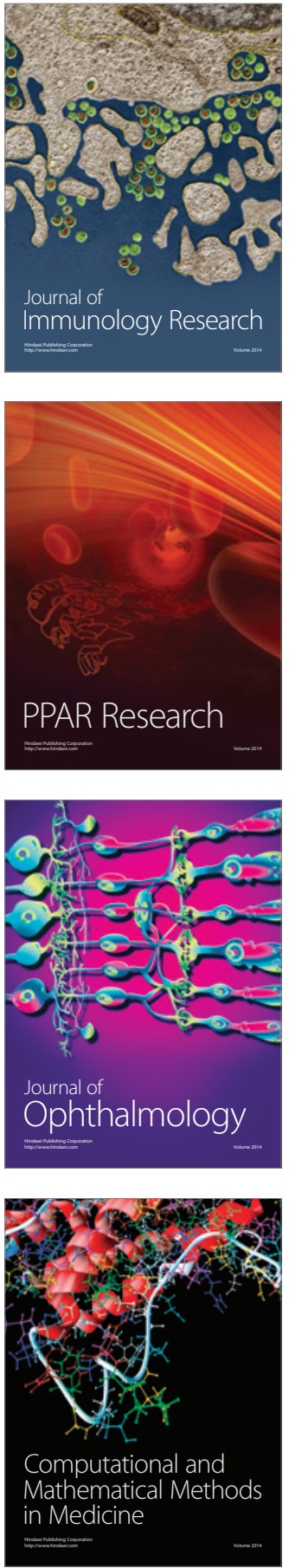

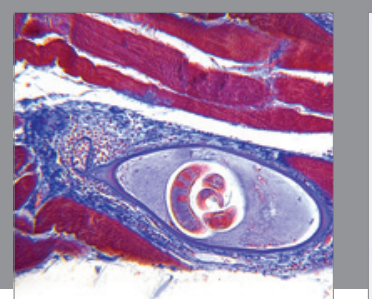

Gastroenterology Research and Practice

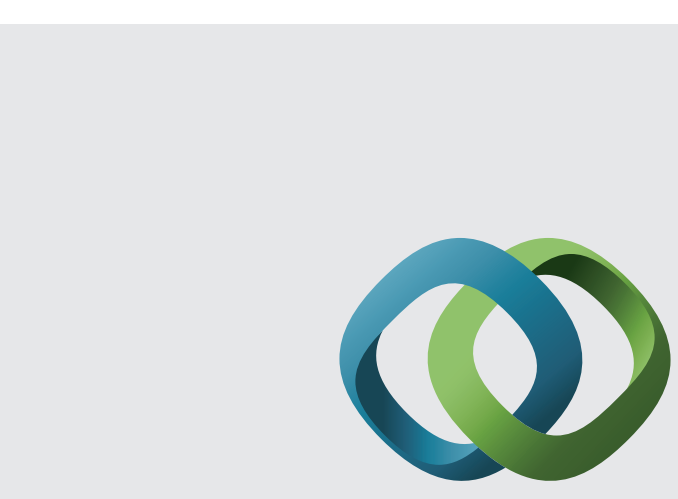

\section{Hindawi}

Submit your manuscripts at

http://www.hindawi.com
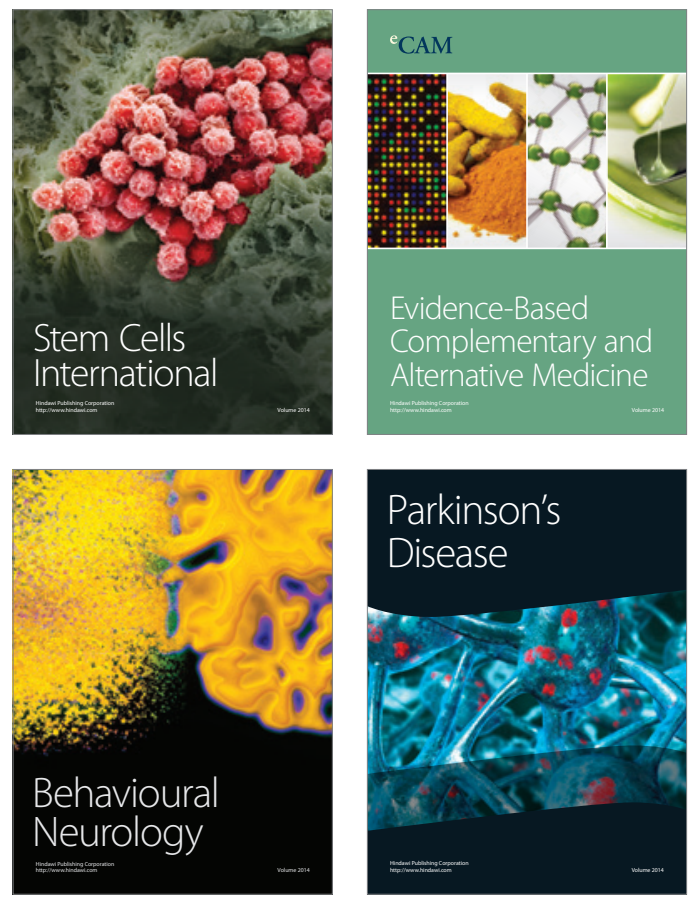
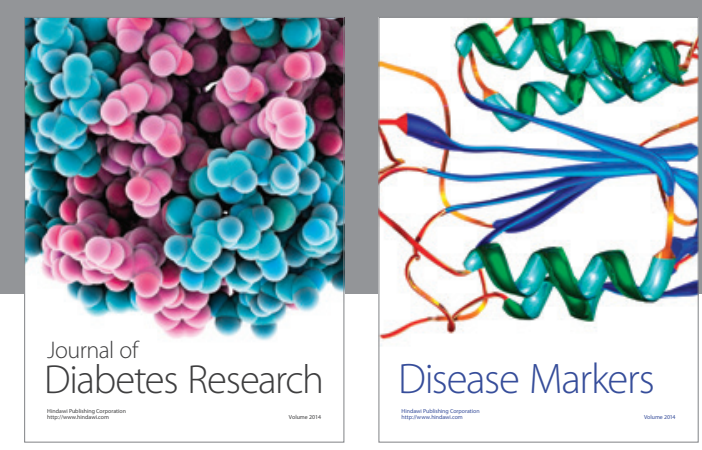

Disease Markers
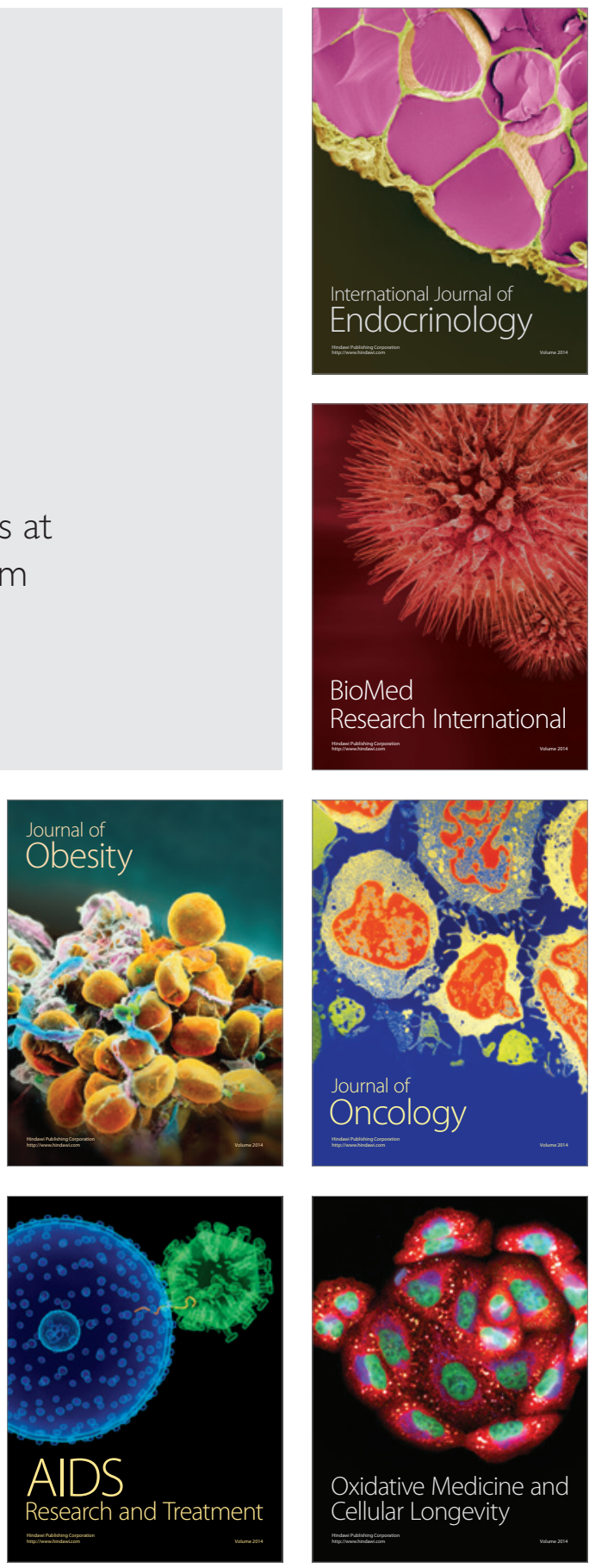